\title{
Addressing environmental sustainability of biochemicals
}

Ögmundarson, Ólafur; Herrgård, Markus J.; Forster, Jochen; Hauschild, Michael Zwicky; Fantke, Peter

Published in:

Nature Sustainability

Link to article, DOI:

$10.1038 / \mathrm{s} 41893-019-0442-8$

Publication date:

2020

Document Version

Peer reviewed version

Link back to DTU Orbit

Coitation (APA):

Ögmundarson, Ó., Herrgård, M. J., Forster, J., Hauschild, M. Z., \& Fantke, P. (2020). Addressing environmental sustainability of biochemicals. Nature Sustainability, 3, 167-174. https://doi.org/10.1038/s41893-019-0442-8

\section{General rights}

Copyright and moral rights for the publications made accessible in the public portal are retained by the authors and/or other copyright owners and it is a condition of accessing publications that users recognise and abide by the legal requirements associated with these rights.

- Users may download and print one copy of any publication from the public portal for the purpose of private study or research.

- You may not further distribute the material or use it for any profit-making activity or commercial gain

- You may freely distribute the URL identifying the publication in the public portal

If you believe that this document breaches copyright please contact us providing details, and we will remove access to the work immediately and investigate your claim 


\title{
Addressing environmental sustainability of biochemicals
}

\author{
Ólafur Ögmundarson ${ }^{1,2}$, Markus J. Herrgård ${ }^{1}$, Jochen Förster ${ }^{1,3}$, Michael Z. Hauschild ${ }^{2}$ \\ and Peter Fantke ${ }^{2 \star}{ }^{2 \star}$
}

Producing biochemicals from renewable resources is a key driver for moving towards sustainable societies. Life cycle assessment (LCA) is a standardized tool to measure related progress by quantifying environmental sustainability performance of chemical products along their life cycles. We analysed LCA studies applied to commercialized commodity biochemicals produced through microbial fermentation. The few available studies show inconsistencies in coverage of environmental impacts and life cycle stages, with varying conclusions. Claims of better sustainability performance of biochemicals over fossil-based chemicals are often based on comparing global warming impacts, while ignoring other impacts from bio-feedstock production. To boost sustainable biochemicals, we recommend that LCA practitioners include the broader range of impact indicators and entire life cycles, follow standards and guidance, and address missing data. The biochemicals industry should systematically use LCA to direct research, identify impact hotspots, and develop methods to estimate full-scale process performance. This will promote biotechnology as important contributor to solving existing sustainability challenges.

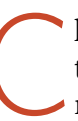
hemicals are an essential part of our every-day life. During the last two decades, global chemicals production doubled, reaching 2.3 billion tonnes in 2017 , while only $2 \%$ are currently bio-based ${ }^{1}$. The continuous dependency on processing fossil resources is a major contributor to greenhouse gas emissions driving global warming impacts ${ }^{2}$. Furthermore, fossil-based chemical production is very energy demanding, accounting for roughly $20 \%$ of the total energy used by industry ${ }^{3}$. Significant investments support exploring renewable 'bio-based' resources as new ways of producing chemicals, which have been reported to cause less global warming impacts than their fossil-based counterparts ${ }^{4}$. This picture, however, is strongly influenced by the covered processes and choice of end-of-life treatment, where global warming impacts from biobased chemicals can also exceed those from fossil-based chemicals when, for example, moving from composting to landfilling without energy recovery $\mathrm{y}^{5,6}$.,

Fighting fossil resources depletion and global warming are the main drivers to shift globally from fossil-based to bio-based products. Industry and academia have jointly taken on the challenge to develop bio-based processes for chemical production, and bio-based chemicals are projected to reach a market share of $22 \%$ by $2025^{1,7}$.

Using non-fossil resources for chemical production comes, however, with its own challenges for environmental sustainability. Feedstock selection, shifting from laboratory to commercial-scale production, and end-of-life treatment of bio-based products may all introduce sustainability trade-offs ${ }^{8}$. To minimize such trade-offs and move biochemicals production to becoming a viable alternative to fossil-based chemicals production, it is crucial to identify and efficiently reduce related environmental impacts by systematically assessing the environmental sustainability performance of biochemical production systems.

More than 10 years ago, the US Department of Energy (DOE) proposed a list of 12 bio-based chemicals as potential substitutes for some of the current fossil-based chemical building blocks on the market, using a techno-economic analysis? The intention was not to directly replace particular intermediates in the chemical industry, but rather use the proposed chemicals as new intermediates for functionally equivalent downstream products, such as packaging materials. Increased use of renewable resources and environmental sustainability of bio-based industrial products were among the DOE's major motivations behind establishing this list ${ }^{10}$. Two chemicals were added and five removed in an update of the original DOE list in 2010, mainly related to shifts in research and development in the biochemical industry ${ }^{11}$. The current level of commercialization of the chemicals on the updated DOE list ranges from laboratory scale to full commercial production ${ }^{12,13}$, with microbial fermentation as a key process for using bio-based feedstocks in the chemical industry ${ }^{13}$. As the DOE list was not developed based on a specific set of criteria, we systematically selected from this list those biochemicals that are currently highly relevant for the global community.

As a result, we focused on studies assessing the environmental performance of commercially available commodity chemicals produced from bio-feedstocks through microbial fermentation as well as assessing the environmental performance of functionally equivalent petrochemicals. We specifically analysed studies applying environmental life cycle assessment (LCA) as a standardized method ${ }^{14}$ widely used to assess the environmental sustainability performance of products and services. LCA aims at capturing all relevant environmental impacts occurring along full product life cycles from raw material extraction ('cradle') and manufacturing to end-of-life ('grave'), and helps pinpointing hotspots in, for example, production processes (see Box 1 for related definitions of LCA terminology). LCA is a powerful tool for identifying trade-offs between life cycle stages and for avoiding burden shifting from impacts on, for example, global warming versus ecotoxicity ${ }^{15}$. We focused on biochemicals that have been fully commercialized to harvest maximum information on reported environmental performance, and exclude biochemicals that are derived

'The Novo Nordisk Foundation Center for Biosustainability, Technical University of Denmark, Kgs. Lyngby, Denmark. ${ }^{2}$ Quantitative Sustainability Assessment, Department of Technology, Management and Economics, Technical University of Denmark, Kgs. Lyngby, Denmark. ${ }^{3}$ Present address: Carlsberg Research Laboratory, Carlsberg A/S, Copenhagen, Denmark. ${ }^{\star}$--mail: pefan@dtu.dk 
Box 1 Important terms from the field of environmental sustainability assessment

Life cycle assessment (LCA). An ISO-standardized method to quantify environmental impacts from inputs (resources used) and outputs (chemical emissions) along the life cycle of one or more defined product or service systems on a common functional basis. LCA consists of four iterative methodological phases, namely goal and scope definition, life cycle inventory analysis, life cycle impact assessment, and interpretation.

Life cycle stages. The stages of product or service life cycles, which usually include raw materials extraction, manufacturing, use, and end-of-life.

Life cycle inventory (LCI) analysis. The phase of LCA quantifying life cycle inputs and outputs for product or service systems as flows from or toward the natural environment.

Life cycle impact assessment (LCIA). The phase of LCA characterizing life cycle inputs and outputs of product or service systems in terms of the magnitude and significance of their potential impacts on human health, ecosystem quality and natural resources.

Impact category. The class of impacts that represent an environmental issue of concern. Examples of impact categories are global warming, ozone depletion, human toxicity, ecotoxicity, land use, water use, and resources use, to which product system life cycle inputs and outputs may be assigned.

Cradle-to-gate. LCA where the product system is defined from raw materials extraction ('cradle') to factory gate, that is, not all life cycle stages are covered.

Cradle-to-grave. LCA where the product system is defined from raw materials extraction ('cradle') to end-of-life ('grave'), that is, all life cycle stages are covered.

End-of-life. Thelife cycle stage representing the end of the product's use. It may include processes like reuse, recycling, chemical and energy recovery, incineration, landfilling, wastewater treatment, and release of bio-based products in nature.

either from chemical conversion or from combined fermentation and chemical conversion (for example, monoethylene glycol), or that are not primarily used as monomers derived for polymerization (for example, ethanol and glycerol). However, the commercialization of bio-based ethanol mainly used for biofuel production and glycerol as a biodiesel production by-product introduced industrial shifts from fossil-based chemicals to biochemicals. Hence, several related LCA studies with focus on environmental performance of biofuels and its by-products exist. In summary, those studies show that using bioresources as compared to fossil-based energy sources reduces greenhouse gas emissions and fossil fuel consumption, while introducing other impacts, such as related to acidification and eutrophication ${ }^{16-20}$. These studies also highlight that methodological choices drive high variability in environmental performance results and limit study comparability. Recommendations derived from LCA literature for ethanol and glycerol are to set future focus on optimizing agricultural methods, identifying cost-effective and environmentally attractive feedstocks, improving pre-treatment operations, and using chemical plant by-products.

With emphasis to go beyond ethanol and glycerol, our study focuses on the following commercialized biochemicals, produced and marketed by at least one company: lactic acid (for example, produced by Cargill, United States), succinic acid (for example, BioAmber, Canada; Succinity, Spain), 1,3-propanediol (for example, DuPont; Tate \& Lyle, both United States), 1,4-butanediol (for example, BioAmber, Canada), and 1,5-pentanediamine, also known as Cadaverine (for example, BASF, China).

In support of the broader development of biochemicals with optimal environmental sustainability performance, we additionally evaluated studies applying LCA to nine DOE listed biochemicals that are not yet commercialized. With our study, we seek to provide answers to three overarching questions: (1) What are the main methodological choices when assessing environmental sustainability of bio-based chemicals? (2) What are the main conclusions from published LCA studies on commercialized bio-based chemicals versus fossil-based chemicals? (3) How can we improve the use of LCA for bio-based chemicals, to help striving towards a viable and sustainable future for the biochemical industry? Based on identified general patterns in environmental impact profiles of bio-based and fossil-based chemicals, we provide specific recommendations for improving future LCA practice, and highlight opportunities and constraints in shifting from fossil-based to bio-based chemicals.

\section{State of commercialized commodity biochemicals}

We systematically searched Scopus and Google Scholar for biochemical name synonyms as listed in PubChem ${ }^{21}$ along with "sustainability" or "LCA" and "life cycle assessment" or "foot print" and "footprint". We found 36 environmental sustainability assessment studies published between 2003 and 2018 that matched these criteria (searches conducted until February 2018). Table 1 summarizes market information and results from these studies conducted for the commercialized biochemicals in focus.

LCA studies have been found for all assessed biochemicals except 1,5-pentanediamine. Of the analysed studies, $83 \%$ claim to follow International Organization for Standardization (ISO) standards, requiring LCA studies to consider all relevant life cycle stages and cover a comprehensive set of environmental issues related to the product system being studied ${ }^{22}$. Nevertheless, $46 \%$ of these studies only consider one or two impact categories and many assess only a limited number of life cycle stages (see Fig. 1 for succinic acid as an example).

Three life cycle stages, namely biomass production, polymer production, and end-of-life treatment, drive LCA results for the five biochemicals with available data (see Table 1), either through a combination of involved processes or high impacts for specific processes. For example, when assessed, land-use impacts are in almost all cases more than a factor of 10 higher for biochemicals than for petrochemicals ${ }^{23-25}$. Variability in life cycle impacts from biochemical production is predominantly driven by geographical differences in the technology mix of the electricity generation ${ }^{26,27}$. During endof-life, impacts vary mainly due to differences in economic development and geographical and cultural waste treatment patterns, yielding a variety of waste disposal options, such as industrial composting, incineration (with or without heat recovery), and landfilling $^{28}$. Impact results variability is further influenced by the choice of allocation approaches in case of multifunctional production systems (system boundary expansion versus economic or energy-allocation-based approaches $)^{29}$. Both geographical and approach-based variability can be tested in scenarios to assess the sensitivity of LCA results and estimate related uncertainty for each scenario, which can help to understand the robustness of results.

Across LCA studies, the single most assessed impact category is global warming from emissions of greenhouse gases. Global warming impacts vary widely when comparing production of lactic acid and (poly)lactic acid (PLA) with functionally equivalent fossilbased chemicals and plastics, such as polyethylene terephthalate (PET) and polystyrene (PS) (see Fig. 2). In a number of studies, PLA shows 5-90\% lower global warming impacts than fossil-based equivalents with higher $\mathrm{CO}_{2}$ emissions due to extraction and processing of fossil resources ${ }^{30,31}$. However, some studies show higher global warming impacts for PLA than for $\mathrm{PET}^{5}$ and $\mathrm{PS}^{6}$, mainly 


\section{Table 1 | Characteristics and LCA results for commercialized biochemicals produced through microbial fermentation}

\begin{tabular}{|c|c|c|c|c|c|}
\hline Chemical name & Lactic acid & Succinic acid & 1,3-propanediol & 1,4-butanediol & 1,5-pentanediamine \\
\hline CAS registry number & $50-21-5$ & $110-15-6$ & $504-63-2$ & $1070-70-8$ & $462-94-2$ \\
\hline \multicolumn{6}{|l|}{$\begin{array}{l}\text { World production in kt } \\
\mathrm{yr}^{-1} \text { (year) }\end{array}$} \\
\hline Fossil-based & $N / A$ & $76(2015)^{56}$ & $N / A$ & $2,500(2015)^{56}$ & $N / A$ \\
\hline Bio-based & $472(2015)^{56}$ & $38(2015)^{56}$ & $128(2015)^{56}$ & $3(2015)^{56}$ & $50^{57,58, a}$ \\
\hline $\begin{array}{l}\text { Main current } \\
\text { application }\end{array}$ & $\begin{array}{l}\text { Food supplement, (poly) } \\
\text { lactic acid }\end{array}$ & $\begin{array}{l}\text { Food supplement, } \\
\text { pigment, resin }\end{array}$ & $\begin{array}{l}\text { Plastics, cosmetics, } \\
\text { cleaning products }\end{array}$ & Plastics, fibres & $\begin{array}{l}\text { Nylon, chemical } \\
\text { intermediate }\end{array}$ \\
\hline $\begin{array}{l}\text { Number of published } \\
\text { LCA studies }\end{array}$ & $\begin{array}{l}20^{\text {b }} \text { (refs. } \\
5,6,23,24,26,28,31,32,39,59-69 \text { ) }\end{array}$ & $8^{c}$ (refs. $29,30,33-36,70,71$ ) & 5 (refs. ${ }^{10,29-32}$ ) & 3 (refs. ${ }^{36,37,71}$ ) & - \\
\hline
\end{tabular}

Number of published LCA studies addressing different impact categories according to ISO14040 and EN16760 requirements ${ }^{d}$

\begin{tabular}{|c|c|c|c|c|c|}
\hline Global warming & 20 & 7 & 5 & 3 & - \\
\hline Ozone formation & 3 & 2 & 1 & 1 & - \\
\hline Ozone depletion & 4 & 3 & - & 1 & - \\
\hline lonizing radiation & 1 & 1 & - & - & - \\
\hline Particle formation & 3 & 2 & 1 & 1 & - \\
\hline Human toxicity & 4 & 3 & 1 & - & - \\
\hline Ecotoxicity & 4 & 3 & 1 & - & - \\
\hline Acidification & 7 & 2 & 2 & 1 & - \\
\hline Eutrophication & 6 & 3 & 1 & 1 & - \\
\hline Land use & 2 & 3 & 1 & - & - \\
\hline Water use & 4 & 1 & - & 1 & - \\
\hline Resources use & 2 & 3 & - & 1 & - \\
\hline Energy demand & 13 & 6 & 5 & 2 & - \\
\hline $\begin{array}{l}\text { Production with } \\
\text { fermentation } \\
\text { from renewable } \\
\text { biomass: state of } \\
\text { commercialization }\end{array}$ & Commercialized ${ }^{12}$ & Commercialized ${ }^{12,72}$ & Commercialization ${ }^{12,72}$ & Commercialized ${ }^{12,72}$ & Commercialized $^{57}$ \\
\hline $\begin{array}{l}\text { Availability of inventory } \\
\text { data for bio-based } \\
\text { production routes }\end{array}$ & $\begin{array}{l}\text { Production process } \\
\text { data in } \mathrm{LCl} \text { database } \\
\text { ecoinvent }^{45}\end{array}$ & $\begin{array}{l}\text { No data in } \mathrm{LCl} \\
\text { databases }\end{array}$ & $\begin{array}{l}\text { No data in } \mathrm{LCl} \\
\text { databases }\end{array}$ & $\begin{array}{l}\text { No data in } \mathrm{LCl} \\
\text { databases }\end{array}$ & No data in $\mathrm{LCl}$ databases \\
\hline $\begin{array}{l}\text { Limitations of available } \\
\text { LCA studies with } \\
\text { focus on assessing } \\
\text { environmental impacts } \\
\text { of biochemicals }\end{array}$ & $\begin{array}{l}\text { Variation in assessed life } \\
\text { cycle stages: two studies } \\
\text { assess stages from } \\
\text { resource extraction to } \\
\text { acid production. } 11 \text { include } \\
\text { polymerization and } 11 \\
\text { assess the whole life cycle. }\end{array}$ & Few studies available & Few studies available & Few studies available & $\begin{array}{l}\text { No LCA studies publicly } \\
\text { available. } \\
\text { Nothing about } \\
\text { environmental } \\
\text { performance is known. }\end{array}$ \\
\hline
\end{tabular}

Opportunities for applying LCA Conduct and publish more studies identifying hotspots and burden shifting within the life cycles; more focused research will help increasing environmental sustainability of bio-based substances. Apply and publish LCA studies on bio-based products and processes. ${ }^{a}$ Estimated production volume. ${ }^{b} \mathrm{Global}$ warming and energy demand impact results could only be retrieved from Morales et al. ${ }^{32}$. 'One of the studies is not an LCA, but a comparison of selected environmental sustainability metrics ${ }^{33}$. 30 out of 36 studies followed ISO standard for conducting LCA. N/A, not applicable.

associated with $\mathrm{CO}_{2}$ emissions from electricity generation (due to a fossil-based electricity generation used for the resin production $\left.{ }^{26}\right)$ and from waste management ${ }^{32,33}$. For succinic acid, global warming impacts for bio-based production vary from being $22 \%$ lower to being $250 \%$ higher than for fossil-based production as a function of considering carbon storage during biomass cultivation, different energy mixes during resin production ${ }^{29}$, and purification technol$\mathrm{ogy}^{34}$. Going beyond global warming, we observe similar trends and variations with both lower and higher impacts for biochemical solutions compared to their fossil-based counterparts, as summarized in Fig. 2 for all considered chemical-impact combinations.

Burden shifting between life cycle stages is an often-disregarded phenomenon when analysing the transition from fossil-based to bio-based chemicals. A cradle-to-gate LCA shows, for example, that global warming impacts from a PLA bottle reach only $69-90 \%$ of impacts from a PET bottle ${ }^{6}$. When including disposal (cradleto-grave), the total burden for PLA increases and shifts from 'harvesting and production' to 'use and end-of-life', due to emissions of the strong greenhouse gas methane from degradation of PLA under anaerobic conditions during landfilling, whereas PET is assumed non-degradable $e^{6}$. The advantage of PET over PLA is further increased when the bottle material is recycled, since such systems are currently operational in many places for PET but not for PLA. An additional shift in burden is seen when moving to biobased lactic acid, where we see strongly reduced global warming impacts for the acid production but strongly increased land-use impacts, which may be up to more than 100-times higher when using agricultural crop-based feedstock (see Fig. 2).

For succinic acid, LCA studies show that fermentation-related energy consumption, choice of fermentation process, and impacts 


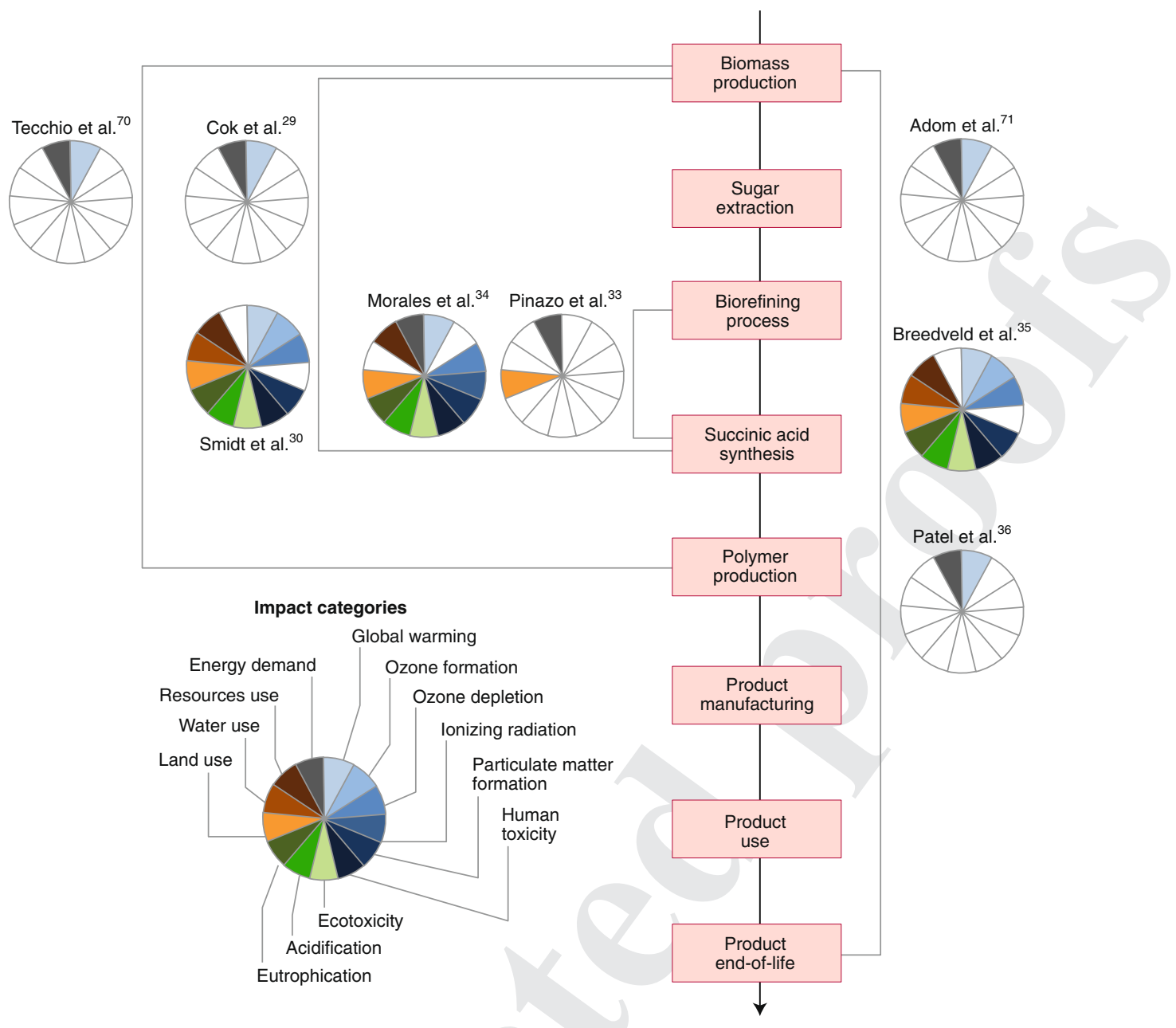

Fig. 1 | Overview of seven existing LCA studies of succinic acid production with their respective life cycle stages and impact categories considered. A full list of included studies is provided in Table 1. Note that the study of Pinazo et al..$^{33}$ is not an LCA (see Table 1 footnote).

from end-of-life processes constitute the main environmental performance challenges when moving to biochemicals ${ }^{29,35,36}$. Studies for 1,4-butanediol and 1,3-propanediol show more consistent environmental benefits of the bio-based chemicals over their petrochemical equivalents. This is mainly linked to petrochemical conversion processes being more energy intensive ${ }^{37}$, while including biomassproduction-related impacts, such as land use and acidification, results in bio-based chemicals either performing worse ${ }^{24}$ or results not being very decisive ${ }^{37}$.

In summary, results for even the most often included impact category, global warming, vary a lot across bio-based chemicals (see Fig. 2), rendering generic conclusions impossible without considering all life cycle states in all cases. In addition, LCA studies need to consider other potentially important impacts, such as land use and eutrophication, associated with current bio-based production methods to ensure that they identify and address relevant impact trade-offs and burden shifting along the chemicals' life cycles.

\section{Improving LCA practice for biochemicals}

The large variation in considered impacts and life cycle stages across LCA studies reflects current challenges when assessing biochemicals. Each studied system is unique in features and components, rendering it difficult to compare it with functionally equivalent systems or processes. This well-known problem, however, is not unique to biochemicals but applies to many product systems, such as waste treatment systems ${ }^{38}$. For improving LCA practice for biochemicals, we emphasize the key components to be included in each study, such as all life cycle stages, including end-of-life scenarios, and all relevant impact categories. Indeed, it is an ISO requirement that all life cycle stages should be considered in an $\mathrm{LCA}^{39}$ to uncover possible burden shifting along product life cycles, such as environmental benefits or impacts related to certain end-of-life treatments. In the following, we detail the required adaptations of LCA for the biochemicals industry to allow giving a relevant impression of environmental sustainability, including to adhere to existing assessment standards and available practical guidance, and to address the need to estimate currently missing data.

Considering the entire life cycle. The analysis of existing LCA studies on biochemicals revealed that the most relevant impact categories are global warming, land use and water use, eutrophication (fertilizer use) and ecotoxicity (pesticide use) during feedstock production, and energy and water use in biorefineries. The most relevant and variable life cycle stage is feedstock production, where a potentially very important modelling aspect is the impacts from indirect land-use changes, representing those changes in land use that may result from expansions in cropland induced by an increased demand for crops due to increases in biochemical (or biofuel) production. Biochemical processing has significant potential for sustainability optimization that becomes even more important during upscaling from laboratory to market scale, where the biochemicals industry will still need further innovation for process 


\begin{tabular}{|c|c|c|c|c|c|c|c|c|c|c|c|}
\hline \multirow[b]{3}{*}{$\begin{array}{l}\text { Impact } \\
\text { category }\end{array}$} & \multicolumn{3}{|c|}{ Lactic acid } & \multicolumn{3}{|c|}{ Succinic acid } & \multicolumn{2}{|c|}{ 1,3 propanediol } & \multicolumn{2}{|c|}{1,4 butanediol } & \\
\hline & \multicolumn{10}{|c|}{ Life cycle stages included in studies } & \multirow{4}{*}{ Factor of difference } \\
\hline & $\begin{array}{c}\text { Acid } \\
\text { production }\end{array}$ & $\begin{array}{l}\text { Polymeri- } \\
\text { zation }\end{array}$ & $\begin{array}{l}\text { End-of-life } \\
\text { scenario }\end{array}$ & $\begin{array}{c}\text { Acid } \\
\text { production }\end{array}$ & $\begin{array}{l}\text { Polymeri- } \\
\text { zation }\end{array}$ & $\begin{array}{l}\text { End-of-life } \\
\text { scenario }\end{array}$ & $\begin{array}{c}\text { Diol } \\
\text { production }\end{array}$ & $\begin{array}{l}\text { End-of-life } \\
\text { scenario }\end{array}$ & $\begin{array}{c}\text { Diol } \\
\text { production }\end{array}$ & $\begin{array}{l}\text { End-of-life } \\
\text { scenario }\end{array}$ & \\
\hline GW & 2 & 11 & 11 & 4 & 1 & 2 & 4 & 2 & 1 & 2 & \\
\hline OF & 1 & 1 & 1 & 1 & & 1 & 1 & & 1 & & \\
\hline OD & 1 & 1 & 2 & 1 & & 1 & & & 1 & & $>10 \uparrow$ Bio-based \\
\hline IR & 1 & & & & & & & & & & 10 \\
\hline PM & 1 & 1 & 1 & 1 & & & 1 & & 1 & & 2 \\
\hline HT & 1 & 2 & 1 & 1 & & 1 & 1 & & & & Bio $\approx$ fossil \\
\hline ET & 1 & 1 & 2 & 1 & & 1 & 1 & & & & 2 \\
\hline$A C$ & 1 & 4 & 3 & & & 1 & 2 & & 1 & & 10 \\
\hline EU & 1 & 3 & 3 & 1 & & 1 & 1 & & 1 & & $>10 \downarrow$ better \\
\hline LU & 1 & & 1 & & & 1 & 1 & 1 & & & No data \\
\hline WU & 1 & 3 & & 1 & & & & & 1 & & \\
\hline $\mathrm{RU}$ & 1 & & 1 & 1 & & 1 & & & 1 & & \\
\hline ED & & 9 & 3 & 3 & 1 & 1 & 4 & 2 & & 2 & \\
\hline
\end{tabular}

Fig. 2 | Environmental impact comparison for chemicals with available data from published studies. Numeric values represent study count. Impacts are expressed as factors of difference between bio-based and fossil-based chemicals (colour range, normalized to fossil-based chemicals) for different chemical-process-impact combinations, where each listed process includes also its upstream processes. Different colours within a single combination (for example, eutrophication (EU) impacts associated with acid production of succinic acid) indicate that multiple scenarios in a single study (that is, indicated study count $n=1$ ) or results of multiple studies (that is, study count $n>1$ ) show different impact ratios for the same chemical-process-impact combination. This variability is plotted as a colour range. A list of all studies included in our analysis is given in Table 1. Impact categories: GW, global warming; OF, photochemical ozone formation; OD, stratospheric ozone depletion; IR, ionizing radiation; $\mathrm{PM}$, particulate matter formation; $\mathrm{HT}$, human toxicity; ET, ecotoxicity (terrestrial or aquatic); AC, acidification (terrestrial or aquatic); EU, eutrophication (terrestrial or aquatic); LU, land use; WU, water use; RU, abiotic resources use; ED, (non-renewable) cumulative energy demand.

maturation. Finally, end-of-life treatment is relevant, as biodegradable chemicals are often claimed to be $\mathrm{CO}_{2}$ emission neutral, but methane emissions from landfilling can offset these benefits.

Because of the special nature of bio-based chemicals originating from biotic resources, all impact categories assessing impacts occurring in the growing phase of the biomass should be included by default in related LCA studies. For end-of-life scenarios, it is especially important to consider those impact categories that address possible toxicity-related impacts of waste treatment including ecotoxicity and human toxicity, and to model potential landfill emissions of methane, a strong greenhouse gas. Spatial variability may have a significant influence on LCA results, and it should be considered whenever data and models are available, in particular for locally variable impact categories like freshwater use, eutrophication and ecotoxicity.

When assessing end-of-life scenarios, the most representative setups for relevant product applications should be included, as environmental impacts can vary greatly between disposal methods ${ }^{26,38}$. If end-of-life scenarios are not considered, it is still important to outline applicable scenarios, stating whether products are compostable, biodegradable under environmentally relevant conditions, or recyclable.

Adhering to existing standards and guidelines. Inconsistent application of well-defined guidelines yields highly variable LCA results even when the same impact categories are assessed ${ }^{40}$. To avoid such issues and to strengthen the credibility of LCA results for biochemicals, we strongly suggest that future studies follow the ISO 14040 standards series and the US Environmental Protection Agency (EPA) LCA principles and practice ${ }^{41}$. Furthermore, for making LCA on bio-based chemicals much more representative, we recommend to follow the specific standard EN 16760:2015 $5^{42}$ for LCA on bio-based products. This standard builds on the ISO standards ${ }^{14,22}$ for guidance concerning the general LCA methodology, but gives explicit guidance, for example, on modelling of agriculture, forestry and aquaculture systems, which are recognized to have relevant environmental impacts in bio-based production systems ${ }^{42}$.

Overall, a strength of LCA is its broad coverage of impact categories, ensuring that all relevant impacts are reflected in the results. It is, however, also a challenge to communicate the array of results. Hence, the choice between alternative products based on LCA results will often require some aggregation of the results across impact categories, based on normalization and weighting of the impact scores or science-based translation into common metrics representing damages to natural ecosystems (for example, species loss) or human health (lifetime loss) ${ }^{43}$. Comprehensive guidance to address these challenges of interpreting LCA results and using these results as decision support for the biochemicals industry is available, for example, in the textbook Life Cycle Assessment: Theory and Practice ${ }^{44}$.

Estimating missing data. In the absence of real-world data, which is often the case for lab-scale production processes, reference process data, default optimization potentials and relevant scale-up mechanisms should be considered for a first impact hotspot screening. Data then need to be systematically provided for hotspot processes and related impacts.

We have the following recommendations for modelling feedstocks. Focus should firstly be on impacts from emissions of pesticide and fertilizer production. Secondly, emissions from pesticide and fertilizer field application should be modelled, as well as use of water, land and global warming impacts (related to for example, 
agricultural methane emissions), which may be estimated based on average conditions and agricultural practices as done, for example, in the ecoinvent database ${ }^{45}$. When data are missing for modelled processes or when focus is on process specifications, computational simulations should be applied to project or quantify emissions, for example for agricultural practices, or by applying techno-economic assessments for biochemical production processes. For addressing geographic differentiation, modelling of emissions and resources use needs to be performed for the specific processes of the life cycle (possibly based on modification of generic inventory database processes and using local electricity grid mixes). In the impact assessment part, spatially differentiated methods are generally available for all non-global impact categories. Hence, impact assessment research is already focused on strengthening the available methods, for example by addressing spatial differentiation of life cycle toxicity impacts ${ }^{46}$, while several related research gaps still remain to be addressed ${ }^{47}$.

For production efficiency, specific data should be available for the studied system and upscaling, and learning may be relevant to consider when comparing new and early-stage technologies with conventional alternatives, depending on the scale and maturity of the processes included. For the impact assessment, we can also a priori identify the relevant impact categories when we know the specificities of the bio-based chemical life cycle and the conventional chemical(s) that we want to compare. Usually, relevant impact categories are found among climate change $\left(\mathrm{CO}_{2}, \mathrm{~N}_{2} \mathrm{O}\right.$ and $\mathrm{CH}_{4}$ related to agriculture and energy systems) and eutrophication (nutrient emissions from agricultural fertilizer application). Of further relevance are impacts associated with ecotoxicity (pesticides emitted from agricultural production of feedstock, biocides emitted from the production of bio-based chemicals, and toxic intermediates potentially emitted from synthesizing fossil-based chemicals), water use (from agriculture if water is critical in the concerned region) and land use (agriculture again).

\section{Toward a sustainable biochemicals industry}

We identified several environmental sustainability recommendations for the biochemicals industry. Key opportunities are: (1) to systematically include LCA at early stages for directing research efforts in support of identifying key environmental hotspots and improving process development; (2) to focus on estimating commercial-scale production process data for biochemicals to allow for developing LCA for a broader range of products; and (3) to use LCA results to promote biotechnology as a significant contributor to solving environmental sustainability problems in areas where they are documented to actually perform better compared to petrochemical solutions. In the production of agricultural feedstocks, this could, for example, mean to increase crop yields and reduce fertilizer consumption by using plant growth promoting bacteria.

LCA for identifying hotspots and research needs. Bio-based chemicals can show lower, but sometimes also higher global warming impacts compared to fossil-based chemicals, for example, due to cultivation practices leading to increased release of carbon from the cultivated soil, and often show higher impacts in other categories, such as land use. However, in full cradle-to-grave assessments, biochemicals often yield a better environmental performance than fossil-based chemicals. When life cycle stages beyond factory gate are assessed, this picture becomes less clear, while for land use specifically, biochemicals always show a worse environmental performance.

LCA is a useful tool to identify hotspots in environmental sustainability profiles of bio-based chemicals ${ }^{48}$. Significant additional research and development efforts are required, mainly regarding feedstock production, biorefining and product recycling, for further improving the overall environmental sustainability of biobased products.

At the early stages of biorefinery development, feasibility studies should include at least screening-level LCA to identify major hotspots in the product system. For assessments where the purpose is to investigate the consequences at societal scale of a change towards first generation bio-based chemicals, LCA should also aim to model the consequences at societal scale, and further modelling efforts are required to address indirect land-use change impacts. As an example, an increased demand for corn to produce bio-based chemicals in the United States may lead to the expansion of corn production to other regions to meet overall greater demand. This may eventually induce conversion of natural areas into farmed land ${ }^{49}$, causing environmental impacts that are potentially large but typically not considered in LCA of individual biochemical products and materials analysed in the present study. Finally, the 'wicked nature of sustainability ${ }^{50}$ calls for considering consumer preferences to a higher degree ${ }^{51}$, since traditional methods targeting optimization as an economic problem at process or product level might not be sufficient, and multidisciplinary approaches (for example, taking into account market-related rebound effects) are necessary to boost overall environmental sustainability of bio-based products ${ }^{52}$.

Methods for full scale process performance. When assessing opportunities using lignocellulosic biomass, macro- and microalgae as next generation feedstocks, the main challenges are related to data availability and accessibility, as well as targeting environmental sustainability-related impact hotspots in biochemicals production that may differ between feedstock generations. When assessing environmental impacts of biochemicals produced by early-stage technologies, in order to judge their full potential in a commercial production, we need to effectively scale up laboratory data to be more representative for commercial scale production. We further need to consider potential learning reflecting the optimization potential of bio-based chemicals, as various production processes are currently still immature. The modelling of these developments may be inspired by comparisons of efficiencies and emissions for laboratory scale processes and commercial full-scale processes for other similar biochemicals and materials. It is further possible to define minimum fermentation yield performance and productivity that would be required to become commercially viable, or to softlink process simulation with LCA, enabling plant-wide design by scaling up lab-scale technologies using scaling factors ${ }^{53}$.

Biotechnology's sustainability potential. In perspective, we observe that socio-economic aspects including population, transportation, and the use of primary energy, water, fertilizers and biotic and abiotic resources grew rapidly over the last decades ${ }^{54}$. These aspects drive increasing impacts on global warming, ocean acidification, eutrophication, stratospheric ozone depletion, and impacts on humans and ecosystems from chemical emissions, and on depletion or degradation of land, water, fossil and other resources. Some of these trends already exceed Earth's capacity for sustaining the current socio-economic development. Hence, just ever being 'more environmentally sustainable' is not enough, especially when population and per-capita consumption are increasing globally ${ }^{52}$. The biochemicals industry should be promoted to explore how innovation can contribute to being environmentally sustainable in absolute terms based on the capacity of sustaining our biophysical Earth systems, while meeting the growing needs for viable bulk chemicals in today's and future societies ${ }^{55}$. For LCA practitioners, this means that there is no excuse not to look at all relevant impacts and life cycle stages to fully supporting a comprehensive improvement of biochemicals' environmental performance. For biotechnology developers, this means to better integrate LCA as a systematic tool that can quantitatively support 
a truly sustainable development of biochemicals instead of relying on partially justifiable environmental sustainability claims, such as reduction of $\mathrm{CO}_{2}$ emissions in the chemical production phase alone compared to a petrochemical alternative. We look forward to seeing both fields converging for successfully moving towards a true sustainable future based on biochemicals in line with the global sustainability agenda.

Received: 13 June 2018; Accepted: 4 November 2019

\section{References}

1. Aranoff, S. L. et al. Industrial Biotechnology: Development and Adoption by the U.S. Chemical and Biofuel Industries (United States International Trade Commission, 2008).

2. IPCC Climate Change 2013: The Physical Science Basis (eds Stocker, T. F. et al.) (Cambridge Univ. Press, 2013).

3. International Energy Outlook (United States Energy Information Administration, 2016)

4. Khoo, H. H., Ee, W. L. \& Isoni, V. Bio-chemicals from lignocellulose feedstock: sustainability, LCA and the green conundrum. Green Chem. 18 1912-1922 (2016).

5. Papong, S. et al. Comparative assessment of the environmental profile of PLA and PET drinking water bottles from a life cycle perspective. J. Clean. Prod. 65, 539-550 (2014)

6. Leejarkpai, T., Mungcharoen, T. \& Suwanmanee, U. Comparative assessment of global warming impact and eco-efficiency of PS (polystyrene), PET (polyethylene terephthalate) and PLA (polylactic acid) boxes. J. Clean. Prod. 125, 95-107 (2016).

7. Biddy, M. J., Scarlata, C. \& Kinchin, C. Chemicals from Biomass: A Market Assessment of Bioproducts with Near-Term Potential (National Renewable Energy Laboratory, 2016).

8. Hottle, T. A., Bilec, M. M. \& Landis, A. E. Sustainability assessments of bio-based polymers. Polym. Degrad. Stabil. 98, 1898-1907 (2013).

9. Werpy, T. et al. Top Value Added Chemicals From Biomass Volume 1-Results of Screening for Potential Candidates From Sugars and Synthesis Gas (US Department of Energy, 2004).

10. Biomass Research and Development Act of 2000 (United States Department of Energy, 2000).

11. Bozell, J. J. \& Petersen, G. R. Technology development for the production of biobased products from biorefinery carbohydrates-the US Department of Energy's “Top 10" revisited. Green Chem. 12, 539-554 (2010).

12. Choi, S., Song, C. W., Shin, J. H. \& Lee, S. Y. Biorefineries for the production of top building block chemicals and their derivatives. Metab. Eng. 28, 223-239 (2015).

13. Opportunities for the Fermentation-Based Chemical Industry (Deloitte, 2014)

14. ISO 14040 International Standard. Environmental Management - Life Cycle Assessment - Principles and Framework (International Organization for Standardization, 2006)

15. Zhu, Y., Romain, C. \& Williams, C. K. Sustainable polymers from renewable resources. Nature 540, 354-362 (2016).

16. Shonnard, D. R. et al. A review of environmental life cycle assessments of liquid transportation biofuels in the Pan American region. Environ. Manag. 56, 1356-1376 (2015).

17. Cherubini, F. \& Strømman, A. H. Life cycle assessment of bioenergy systems: state of the art and future challenges. Bioresour. Technol. 102, 437-451 (2011).

18. Malça, J. \& Freire, F. Life-cycle studies of biodiesel in Europe: a review addressing the variability of results and modeling issues. Renew. Sustain. Energy Rev. 15, 338-351 (2011).

19. Amiri, T. Y. \& Ghasemzadeh, K. in Ethanol. Science and Engineering (eds Basile, A. et al.) 451-504 (Elsevier, 2019).

20. Lari, G. M. et al. Environmental and economical perspectives of a glycerol biorefinery. Energy Environ. Sci. 11, 1012-1029 (2018).

21. National Center for Biotechnology Information PubCHem (Bethesda, 2018)

22. ISO 14044 International Standard. Environmental Management - Life Cycle Assessment - Requirements and Guidelines (International Organization for Standardization, 2006).

23. Daful, A. G., Haigh, K., Vaskan, P. \& Görgens, J. F. Environmental impact assessment of lignocellulosic lactic acid production: integrated with existing sugar mills. Food Bioprod. Process. 99, 58-70 (2016).

24. Patel, M. et al. Medium and Long-Term Opportunities and Risks of the Biotechnological Production of Bulk Chemicals from Renewable Resources - The Potential of White Biotechnology (Utrecht University, Department of Science, Technology and Society / Copernicus Institute, 2006).

25. Hermann, B. G., Blok, K. \& Patel, M. K. Producing bio-based bulk chemicals using industrial biotechnology saves energy and combats climate change. Environ. Sci. Technol. 41, 7915-7921 (2007).
26. Suwanmanee, U. et al. Life cycle assessment of single use thermoform boxes made from polystyrene (PS), polylactic acid, (PLA), and PLA/starch: cradle to consumer gate. Int. J. Life Cycle Assess. 18, 401-417 (2013).

27. Isola, C. et al. Life cycle assessment of photodegradable polymeric material derived from renewable bioresources. J. Clean. Prod. 142, 2935-2944 (2017).

28. Madival, S., Auras, R., Singh, S. P. \& Narayan, R. Assessment of the environmental profile of PLA, PET and PS clamshell containers using LCA methodology. J. Clean. Prod. 17, 1183-1194 (2009).

29. Cok, B., Tsiropoulos, I., Roes, A. L. \& Patel, M. K. Succinic acid production derived from carbohydrates: an energy and greenhouse gas assessment of a platform chemical toward a bio-based economy. Biofuels Bioprod. Bioref. 8, 16-29 (2014).

30. Smidt, M. et al. in Sustainability Assessment of Renewables-Based Products (eds Dewulf, J., De Meester, S. \& Alvarenga, R. A. F.) 307-321 (John Wiley \& Sons, 2016)

31. Groot, W. J. \& Borén, T. Life cycle assessment of the manufacture of lactide and PLA biopolymers from sugarcane in Thailand. Int. J. Life Cycle Assess. 15, 970-984 (2010)

32. Morales, M. et al. Environmental and economic assessment of lactic acid production from glycerol using cascade bio- and chemocatalysis. Energy Environ. Sci. 8, 558-567 (2015).

33. Pinazo, J. M., Domine, M. E., Parvulescu, V. \& Petru, F. Sustainability metrics for succinic acid production: a comparison between biomass-based and petrochemical routes. Catal. Today 239, 17-24 (2015).

34. Morales, M. et al. Sustainability assessment of succinic acid production technologies from biomass using metabolic engineering. Energy Environ. Sci. 9, 2794-2805 (2016)

35. Breedveld, L. et al. In Proc. 9th International Conference on Life Cycle Assessment in the Agri-Food Sector (LCA Food 2014) (eds Schenck, R. \& Huizen, D.) 157-166 (American Center for Life Cycle Assessment, 2014).

36. Patel, M. K. et al. Second-generation bio-based plastics are becoming a reality - non-renewable energy and greenhouse gas (GHG) balance of succinic acid-based plastic end products made from lignocellulosic biomass. Biofuels Bioprod. Bioref. 12, 426-441 (2018).

37. Forte, A., Zucaro, A., Basosi, R. \& Fierro, A. LCA of 1,4-butanediol produced via direct fermentation of sugars from wheat straw feedstock within a territorial biorefinery. Materials 9, 563 (2016).

38. Laurent, A. et al. Review of LCA studies of solid waste management systems - part I: lessons learned and perspectives. Waste Manag. 34, 573-588 (2014).

39. Vink, E. T. H. \& Davies, S. Life cycle inventory and impact assessment data for 2014 Ingeo $^{\text {ns }}$ polylactide production. Ind. Biotechnol. 11, 167-180 (2015).

40. Thomassen, G., Van Dael, M., Lemmens, B. \& Van Passel, S. A review of the sustainability of algal-based biorefineries: Towards an integrated assessment framework. Renew. Sustain. Energ. Rev. 68, 876-887 (2017).

41. Life Cycle Assessment: Principles and Practice (United States Environmental Protection Agency, 2006).

42. EN 16760:2015: Bio-based Products - Life Cycle Assessment (European Committee for Standardisation, 2015).

43. Hauschild, M. Z. Assessing environmental impacts in a life-cycle perspective. Environ. Sci. Technol. 39, 81A-88A (2005).

44. Hauschild, M., Rosenbaum, R. \& Olsen, S. I. Life Cycle Assessment: Theory and Practice (Springer, 2018).

45. ecoinvent Version 3.5 (ecoinvent, 2018)

46. Wannaz, C., Fantke, P. \& Jolliet, O. Multi-scale spatial modeling of human exposure from local sources to global intake. Environ. Sci. Technol. 52, 701-711 (2018)

47. Mutel, C. et al. Overview and recommendations for regionalized life cycle impact assessment. Int. J. Life Cycle Assess. 24, 856-865 (2019).

48. Kirchain, R. E. Jr, Gregory, J. R. \& Olivetti, E. A. Environmental life-cycle assessment. Nat. Mater. 16, 693-697 (2017).

49. Schmidt, J. H., Weidema, B. P. \& Brandão, M. A framework for modelling indirect land use changes in Life Cycle Assessment. J. Clean. Prod. 99, 230-238 (2015)

50. Bakshi, B. R. The path to a sustainable chemical industry: progress and problems. Curr. Opin. Chem. Eng. 1, 64-68 (2011).

51. Dunn, J. B., Adom, F. K., Sather, N. F. \& Han, J. in Commercializing Biobased Products: Opportunities, Challenges, Benefits, and Risks (ed. Snyder, S. W.) 258-284 (The Royal Society of Chemistry, 2016).

52. Hauschild, M. Z. Better - but is it good enough? On the need to consider both eco-efficiency and eco-effectiveness to gauge industrial sustainability. Procedia CIRP 29, 1-7 (2015).

53. Towler, G. \& Sinnott, R. in Chemical Engineering Design 2nd edn (eds Towler, G. \& Sinnott, R.) 307-354 (Butterworth-Heinemann, 2013).

54. Steffen, W., Broadgate, W., Deutsch, L., Gaffney, O. \& Ludwig, C. The trajectory of the Anthropocene: the great acceleration. Anthropocene Rev. 2, 81-98 (2015).

55. Fantke, P. \& Illner, N. Goods that are good enough: introducing an absolute sustainability perspective for managing chemicals in consumer products. Curr. Opin. Green Sustain. Chem. 15, 91-97 (2019). 
56. From the Sugar Platform to Biofuels and Biochemicals (European Commission Directorate-General Energy, 2015).

57. Cathay Industrial Biotech Ltd. Cathay Industrial Biotech Ltd. announces ground-breaking and agreement signing for significant expansion in bio-produced monomer and polyamide production. PR Newswire / Cision Communication Cloud https://go.nature.com/36IgGDP (June 2016).

58. Aeschelmann, F. \& Carus, M. Bio-based Building Blocks and Polymers (nova-Institut $\mathrm{GmbH}, 2016$ ).

59. Bohlmann, G. M. Biodegradable packaging life-cycle assessment. Environ. Prog. 23, 342-346 (2004).

60. Shen, L., Worrell, E. \& Patel, M. K. Comparing life cycle energy and GHG emissions of bio-based PET, recycled PET, PLA, and man-made cellulosics. Biofuels Bioprod. Bioref. 6, 625-639 (2012).

61. Adom, F. K. \& Dunn, J. B. Life cycle analysis of corn-stover-derived polymer-grade l-lactic acid and ethyl lactate: greenhouse gas emissions and fossil energy consumption. Biofuels Bioprod. Bioref. 11, 258-268 (2017).

62. Ingrao, C. et al. Polylactic acid trays for fresh-food packaging: a carbon footprint assessment. Sci. Total Environ. 537, 385-398 (2015).

63. van der Harst, E., Potting, J. \& Kroeze, C. Multiple data sets and modelling choices in a comparative LCA of disposable beverage cups. Sci. Total Environ. 494-495, 129-143 (2014).

64. Gaudreault, C., Samson, R., Chambost, V. \& Stuart, P. LCA for the engineering analysis of the forest biorefinery. Appita J. 63, 206-230 (2010).

65. Vink, E. T. H., Davies, S. \& Kolstad, J. J. The eco-profile for current Ingeo ${ }^{\circ}$ polylactide production. Ind. Biotechnol. 6, 212-224 (2010).

66. Landis, A. E. in Poly(Lactic Acid): Synthesis, Structures, Properties, Processing, and Applications (eds Auras, R. et al.) 431-441 (John Wiley and Sons, 2010).

67. Gironi, F. \& Piemonte, V. Life cycle assessment of polylactic acid and polyethylene terephthalate bottles for drinking water. Environ. Prog. Sustain. Energy 30, 459-468 (2011).

68. Vink, E. T. H., Rábago, K. R., Glassner, D. A. \& Gruber, P. R. Applications of life cycle assessment to NatureWorks ${ }^{\text {Ti }}$ polylactide (PLA) production. Polym. Degrad. Stabil. 80, 403-419 (2003).
69. Vink, E. T. H., Glassner, D. A., Kolstad, J. J., Wooley, R. J. \& O’Connor, R. P. The eco-profiles for current and near-future NatureWorks ${ }^{\circledast}$ polylactide (PLA) production. Ind. Biotechnol. 3, 58-81 (2007).

70. Tecchio, P., Freni, P., De Benedetti, B. \& Fenouillot, F. Ex-ante life cycle assessment approach developed for a case study on bio-based polybutylene succinate. J. Clean. Prod. 112, 316-325 (2016).

71. Adom, F., Dunn, J. B., Han, J. \& Sather, N. Life-cycle fossil energy consumption and greenhouse gas emissions of bioderived chemicals and their conventional counterparts. Environ. Sci. Technol. 48, 14624-14631 (2014).

72. Lane, J. The DOE's 12 top biobased molecules - what became of them? BiofuelsDigest https://go.nature.com/32rgg12 (April 2015).

\section{Acknowledgements}

This work was supported by the EU FP7 project Biorefine 2G (grant 613771) and by the Novo Nordisk Foundation. We thank S. Sukumara, A. Garcia Sancho and N. Kirchhübel for input to an earlier manuscript draft.

\section{Author contributions}

Ó.Ö. and P.F. organized and structured the work and wrote the manuscript. Ó.Ö. gathered, processed and visualized the data. P.F. contributed to data analysis and visualization, and provided overall guidance. M.J.H., J.F. and M.Z.H. provided background information and edited the manuscript.

\section{Competing interests}

The authors declare no competing interests.

\section{Additional information}

Correspondence should be addressed to P.F.

Reprints and permissions information is available at www.nature.com/reprints. Publisher's note Springer Nature remains neutral with regard to jurisdictional claims in published maps and institutional affiliations.

(c) Springer Nature Limited 2019 